\title{
PELATIHAN AKUPRESUR UNTUK RELAKSASI TUBUH DAN MENGATASI DISMENOREA
}

\author{
Istiqomah Risa Wahyuningsih ${ }^{1)}$, Sri Handayani ${ }^{2)}$ \\ ${ }^{1}$ Kebidanan, STIKES Aisyiyah Surakarta \\ ${ }^{2}$ Kebidanan, STIKES Aisyiyah Surakarta \\ E-mail: istiqomahrw@stikes-aisyiyah.ac.id
}

\begin{abstract}
Acupressure is a technique using touch/contact to balance the energy channels in the body or Qi. Acupressure contests useful for disease prevention, cure, rehabilitation (recovery), relaxation and increase endurance. Acupressure can also be used to treat pain during menstruation (dysmenorrhea). Target and outcome: an increase in knowledge and skills of women, the leaflets about the relaxation of the body and reduce dysmenorrhea, as well as community service articles published. Methods: divided into four sessions, namely working on the pretest, delivery of content and practice of acupressure, question and answer sessions working on the posttest. Submission of material is done by means of lectures and brainstorming as well as the demonstration of acupressure points used. Result: there is an increased knowledge of the pretest and posttest value of the average value before training (pre-test) 32.86 into 71.84 (posttest), in addition to the upgrading of skills seen from acupressure point positioning accuracy.
\end{abstract} Conclusion: The community service is to enhance the knowledge and skills of participants on acupressure to relax the body and overcome dysmenorrhoea.

Keywords: Acupressure; Dysmenorrhea; Relaxation

\section{PENDAHULUAN}

Terapi akupresur (totok) lebih efektif mengurangi nyeri karena memiliki efek analgesic. Terapi akupresur dengan pemijatan atau penekanan pada titik LI 4 (Hegu) dan ST 36 (Zusanli) akan meningkatkan kadar endorphin sehingga lebih cepat menurunkan rasa nyeri (Setyowati, 2018). Pijatan pada daerah punggung bertujuan untuk melancarkan peredaran darah sehingga dapat memberikan efek relaksasi yang berpengaruh terhadap penurunan tingkat nyeri dismenorea (Olivia, 2013).

Inti pengobatan akupressur adalah mengembalikan sistem keseimbangan (homeostasis) tubuh yang terwujud dengan adanya aliran qi yang teratur dan harmonis dalam meridian sehingga klien sehat kembali. Akupresur bermanafaat untuk pencegahan penyakit, penyembuhan penyakit, rehabilitasi (pemulihan) dan meningkatkan daya tahan tubuh. Akupresur juga bermanfaat untuk 


\section{GEMASSIKA: Jurnal Pengabdian Kepada Masyarakat}

Vol. 4 No. 1 Mei 2020

menghilangkan nyeri dan gejala-gejala pada berbagai penyakit, seperti menurunkan low back pain (LBP) dan menurunkan heart rate pada pasien stroke. Akupresur juga dapat digunakan untuk mengatasi nyeri pada saat menstruasi (dismenorea) dan distress menstrual. Terapi akupressur akan menstimulasi sel saraf sensorik di sekitar titik akupresur kemudian diteruskan ke medulla spinalis dan ke mesensefalon serta komplek pituitari hypothalamus yang ketiganya diaktifkan untuk melepaskan hormon endorphin yang dapat memberikan rasa tenang dan nyaman (Setyowati, 2018; Majid dan Rini, 2016).

Dismenorea adalah rasa tidak nyaman atau nyeri pada perut bagian bawah, yang terjadi pada masa awal menstruasi. Dismenorea merupakan menstruasi disertai rasa sakit yang hebat dan kram. Dismenorea berarti menstruasi yang sakit. Dismenorea bisa tersendiri atau merupakan bagian dari sindrom premenstrual. Istilah dismenorea primer dipakai untuk menstruasi yang sakit tanpa ada kaitannya dengan penyebab fisik. Sedangkan dismenorea sekunder ada kaitannya dengan penyebab fisik.

Dismenorea terjadi dua jenis, yaitu dismenorea primer dan dismenorea sekunder. Kasus dismenorea primer sering terjadi kemungkinan lebih dari 50\% wanita mengalaminya dan $15 \%$ diantaranya mengalami nyeri yang hebat. Biasanya dismenorea primer timbul pada masa remaja, yaitu sekitar 2-3 tahun setelah menstruasi pertama dan tidak ada penyakit yang menyebabkannya. Pada dismenorea sekunder, gangguan haid disebabkan adanya gejala penyakit yang berhubungan dengan kandungan, misalnya endometritis, infeksi rahim, kista/polip, tumor sekitar kandungan, kelainan kedudukan rahim yang dapat mengganggu organ dan jaringan di sekitarnya

Berdasarkan data menunjukkan bahwa dismenorea primer tersebut dialami oleh 60$70 \%$ wanita muda.Dari tiga perempat jumlah wanita tersebut mengalami dismenorea dengan intensitas ringan atau sedang. Sedangkan seperempat bagiannya mengalami dismenorea dengan intensitas berat dan terkadang menyebabkan tidak berdaya (dalam menahan nyerinya tersebut).

Dismenorea umumnya menyerang wanita yang sedang mengalami datang bulan. Semakin dewasa wanita, semakin berkurang rasa sakit yang dirasakan. Kondisi ini dapat hilang begitu wanita memiliki bayi. Nyeri haid dapat ditangani dengan mengurangi faktor-faktor risiko. Diskusikan dengan dokter untuk informasi lebih lanjut. Gejala-gejala 
umum dari dismenore adalah nyeri pada perut bawah, kadang terasa intens, terasa tekanan pada perut, nyeri pada pinggang, punggung bawah, atau bagian dalam paha, mual dan muntah, feses yang cair, sakit kepala, serta pusing (Samiadi, 2016)

Nyeri haid disebabkan oleh berkontraksinya otot rahim. Apabila otot berkontraksi terlalu kuat, nyeri muncul akibat putusnya pasokan oksigen pada jaringan otot di rahim. Berikut adalah kondisi yang dapat menyebabkan kram haid antara lain endometriosis: jaringan yang tersambung dengan rahim menjadi menempel dengan bagian luar rahim, biasanya pada tuba fallopi, indung telur atau pelvis, uterine fibroid, adenomyosis: jaringan terhubung dengan rahim bertumbuh hingga ke dinding rahim, menyebabkan rasa sakit, pelvic inflammation disease (PID): bakteri menular seksual dapat menyebabkan infeksi pada organ reproduksi wanita, cervical stenosis: jika bukan cervix kecil yang mempengaruhi aliran menstruasi, menyebabkan rasa sakit dan meningkatkan tekanan pada rahim. Ada banyak faktor risiko untuk dismenorea, yaitu usia di bawah 30 tahun, masa puber mulai sejak usia 11 atau ke bawah, mengalami perdarahan berat atau yang tidak normal selama menstruasi, belum pernah melahirkan, memiliki riwayat nyeri haid dalam keluarga, perokok.
Hasil wawancara dengan beberapa ibuibu yang mengikuti kajian thibbun nabawi ternyata masih banyak dari mereka yang belum mengetahui cara melakukan relaksasi tubuh dan mengurangi dismenorea. Uraian tersebut menjadi dasar dilakukannya pengabdian masyarakat dengan tema akupresur untuk relaksasi tubuh dan dismenorea.

\section{MASALAH, TARGET DAN LUARAN}

Permasalahan kelompok mitra berdasarkan hasil pengamatan dan survei langsung ke lokasi adalah terdapat $85 \%$ ibu-ibu belum mengetahui acupressure untuk relaksasi tubuh dan mengurangi dismenorea, adanya permintaan pengisian materi dan pelatihan untuk ibu-ibu dalam hal acupressure untuk relaksasi tubuh dan mengurangi dismenorea.

Berdasarkan masalah tersebut, solusi yang ditawarkan pada kelompok mitra, untuk membantu memecahkan masalah dengan metode: pelatihan (penyampaian materi dan praktik) acupressure untuk relaksasi tubu dan mengurangi dismenorea.

Target dari kegiatan ini adalah peningkatan pengetahuan dan keterampilan ibu-ibu tentang relaksasi tubuh dan mengurangi dismenorea.

Luaran yang dihasilkan melalui program ini adalah jasa peningkatan keterampilan 
GEMASSIKA: Jurnal Pengabdian Kepada Masyarakat

Vol. 4 No. 1 Mei 2020

akupresur untuk relaksasi tubuh dan mengurangi dismenorea, leaflet serta artikel pengabdian kepada masyarakat.

\section{METODE PELAKSANAAN}

\section{A. Metode Kegiatan}

Kegiatan pelatihan akupresur diawali dengan permohonan ijin pelaksanaan pengabdian kepada masyarakat kepada panitia penyelenggara kegiatan. Kemudian dilanjutkan dengan kesepakatan waktu dan tempat antara pembicara dan penyelenggara kegiatan. Tindak lanjut dari hal tersebut, tim pelaksanan pengabdian kepada masyarakat melakukan persiapan materi, kuesioner pretest dan posttest, persiapan doorprise dan kenang-kenangan.

Pelatihan akupresur untuk relaksasi tubuh dan mengurangi dismenorea dilakukan dengan 4 sesi, yaitu: sesi mengerjakan pre test, penyampaian materi dan praktik akupresur, tanya jawab dan sesi mengerjakan post test. Penyampaian materi dilakukan dengan cara ceramah dan brainstorming serta peragaan terhadap titik-titik akupresur yang digunakan setelah itu dilanjutkan dengan tanya jawab. Sasaran dalam kegiatan ini adalah ibu-ibu dan remaja putri kelompok pengajian di Masjid Jami’ Abdurrahman As-Sanad Jati, Mulur, Sukoharjo.

\section{B. Metode Pemecahan Masalah}

1. Input

Ibu-ibu dan remaja putri yang belum mengetahui akupresur untuk relaksasi tubuh dan mengurangi dismenorea.

2. Proses

Pre test dilanjutkan dengan penyampaian materi sekaligus praktik tentang akupresur untuk relaksasi tubuh dan mengurangi dismenorea kemudian tanya jawab dan diakhiri dengan mengerjakan post test.

3. Output

Adanya peningkatan pengetahuan dan keterampilan ibu-ibu dan remaja putri kelompok pengajian di Masjid Jami’ Abdurrahman As-Sanad Jati, Mulur, Sukoharjo.

\section{HASIL DAN PEMBAHASAN}

Telah dilaksanakan kegiatan pelatihan akupresur untuk relaksasi tubuh dan mengurangi dismenorea pada ibu-ibu dan remaja putri kelompok pengajian di Masjid Jami’ Abdurrahman As-Sanad Jati, Mulur, Sukoharjo. Pelatihan dilakukan pada hari Ahad, tanggal 14 Juli 2019, di Masjid Jami' Abdurrahman As-Sanad Jati, Mulur, Sukoharjo. Indikator keberhasilan kegiatan 
diukur dari banyaknya peserta ibu-ibu dan remaja putri yang menghadiri kegiatan pengabdian masyarakat yaitu berjumlah 107 orang dan antusiasme peserta kegiatan sangat tinggi ditunjukkan dengan adanya peserta yang bertanya saat kegiatan pengabdian 3 orang dan beberapa orang diluar kegiatan berlangsung. Indikator keberhasilan yang lain dilihat dari peningkatan pengetahuan pada nilai pre test dan post test dari nilai rata-rata sebelum pelatihan (pre test) 32,86 menjadi 71,84 (post test), selain itu peningkatan keterampilan dilihat dari ketepatan posisi titik pijat yang dilakukan secara berpasangan antar peserta.

Kegiatan pelatihan dibagi menjadi 4 sesi, yaitu sesi mengerjakan pre test, penyampaian materi dan praktik akupresur, tanya jawab dan sesi mengerjakan post test. Sesi yang pertama semua peserta mengerjakan pre test sebelum dilakukan penyampaian materi dan praktik akupresur. Pengerjaan pre test dengan 20 butir soal pilihan ganda dengan waktu 20 menit.

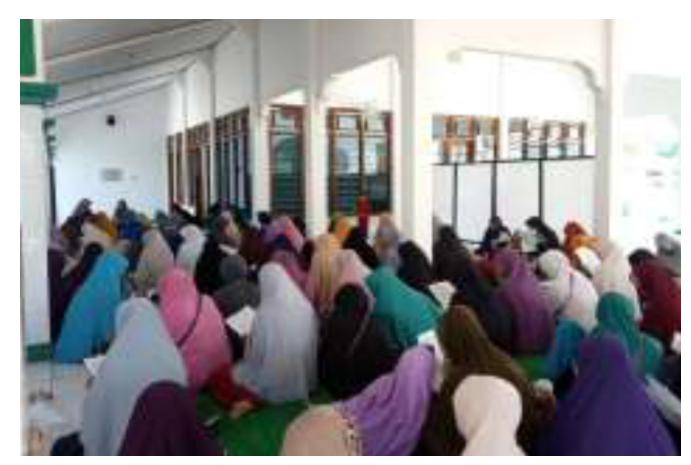

Gambar 1. Peserta mengerjakan pretest
Setelah itu dilanjutkan dengan sesi yang kedua yaitu penyampaian materi dan praktik akupresur. Penyampaian materi dilakukan dengan ceramah dan brainstorming. Brainstorming dilakukan untuk mengetahui sejauh mana pengetahuan peserta tentang akupresur, titik-titik relaksasi tubuh dan titiktitik mengurangi dismenorea secara lisan. Setelah dilakukan penyampaian materi dan brainstorming barulah dilakukan praktik akupresur. Praktik akupresur dilakukan dengan cara berpasangan antar peserta yang duduk di sebelahnya.

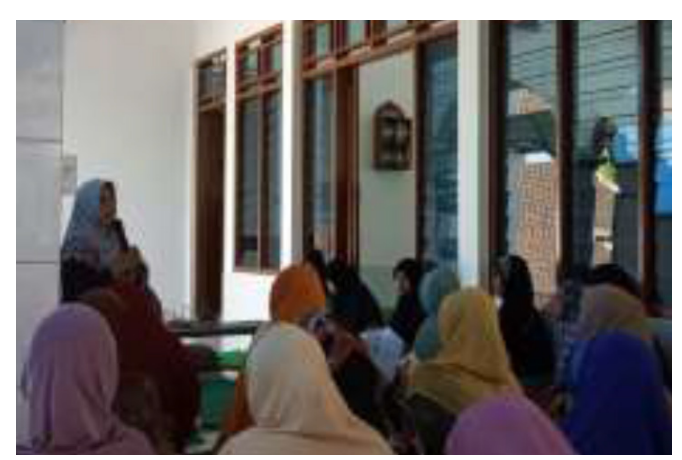

Gambar 2. Penyampaian Materi 2

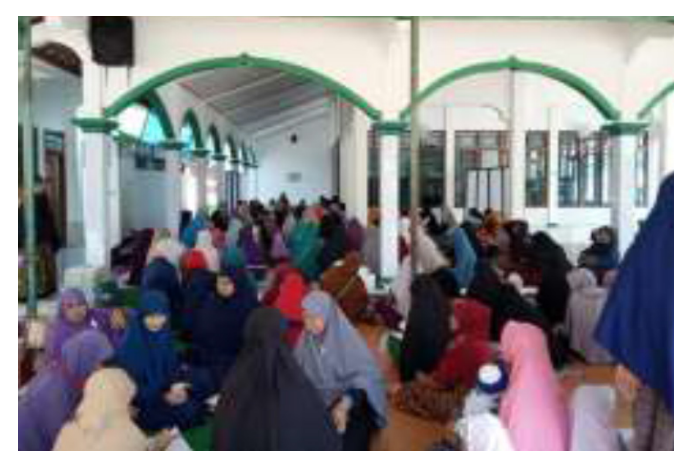

Gambar 3. Praktik Akupresur

Setelah sesi kedua selesai dilanjutkan sesi ke tiga yaitu tanya jawab. Pada sesi tanya 
jawab tahap 1 ada 3 orang penanya dan tahap 2 juga ada 3 orang penanya. Pertanyaan yang disampaikan seputar posisi titik yang tepat, metode pemijatannya, dan waktu dilakukan pemijatan yang tepat. Ada 2 orang penanya meminta untuk ditunjukkan titik-titik untuk relaksasi yang ada pada tubunya dan meminta untuk dilakukan pemijatan sehingga peserta tersebut dapat mengingat titik-titik yang digunakan untuk relaksasi tubuh dan dismenorea.

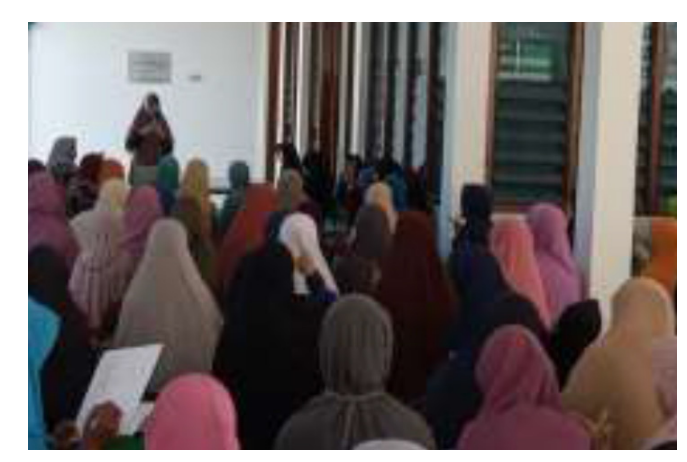

Gambar 4.

Tanya jawab dan pengerjaan Posttest

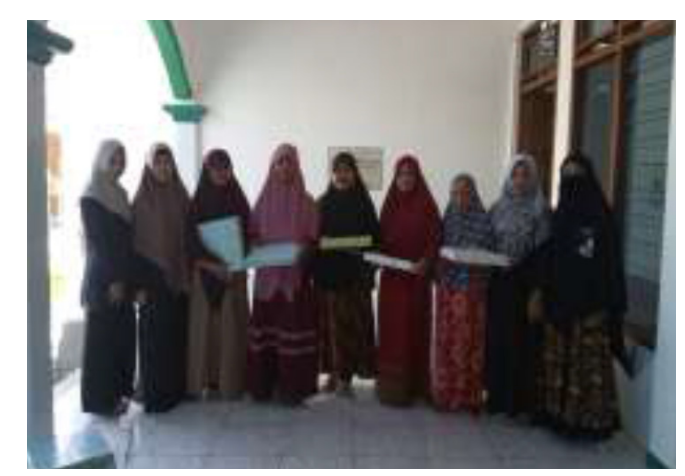

Gambar 5.

Pemberian tali asih kepada peserta yang aktif bertanya

Terapi akupresur (totok) lebih efektif mengurangi nyeri karena memiliki efek analgesic. Terapi akupresur dengan pemijatan atau penekanan pada titik LI 4 (Hegu) dan ST 36 (Zusanli) akan meningkatkan kadar endorphin sehingga lebih cepat menurunkan rasa nyeri (Setyowati, 2018). Pijatan pada daerah punggung bertujuan untuk melancarkan peredaran darah sehingga dapat memberikan efek relaksasi yang berpengaruh terhadap penurunan tingkat nyeri dismenorea (Olivia, 2013).

Inti pengobatan akupressur adalah mengembalikan sistem keseimbangan (homeostasis) tubuh yang terwujud dengan adanya aliran $q i$ yang teratur dan harmonis dalam meridian sehingga klien sehat kembali. Akupresur bermanafaat untuk pencegahan penyakit, penyembuhan penyakit, rehabilitasi (pemulihan) dan meningkatkan daya tahan tubuh. Akupresur juga bermanfaat untuk menghilangkan nyeri dan gejala-gejala pada berbagai penyakit, seperti menurunkan low back pain (LBP) dan menurunkan heart rate pada pasien stroke. Akupresur juga dapat digunakan untuk mengatasi nyeri pada saat menstruasi (dismenorea) dan distress menstrual (Setyowati, 2018).

Akupresur digunakan untuk mengatasi berbagai penyakit. Salah satu kegunaan umumnya adalah meredakan rasa sakit seperti sakit kepala, sakit leher, serta sakit punggung. 
Orang juga menggunakan akupresur untuk membantu mengatasi masalah mual serta muntah-muntah, kelelahan, stres mental dan fisik, menurunkan berat badan, bahkan mengatasi kecanduan. Akupresur dipercaya bisa menghasilkan relaksasi yang mendalam serta mengurangi ketegangan otot. Akupresur juga dapat menurunkan tingkat nyeri haid (dismenorea) primer pada remaja. Stimulasi refleksi yang ditimbulkan dari pemberian akupresur efektif mengurangi nyeri pada dismenore (Yati, 2019; Meita, dkk, 2018; Ridwan dan Herlina, 2015; Julianti,dkk, 2014)

Akupresur biasanya dilakukan dengan jari untuk memijat, menggosok, dan memberi stimulasi pada titik-titik tekan, bisa juga dengan menggunakan kepalan tangan, siku, lutut, betis, serta kaki. Akupresur melibatkan penekanan stabil pada titik-titik energi di tubuh. Dengan menekan sebuah titik hanya selama setengah detik, tubuh akan mulai merespons. Ini adalah cara yang baik untuk mencari titik tekan saat baru saja mulai. Untuk mendapatkan efek maksimal akupresur, tekanlah dan tahan selama setidaknya 2-3 menit. Jika tangan lelah, kurangi tekanan perlahan-lahan, kibas-kibaskan tangan dan tarik napas panjang, kemudian tekan kembali titik tersebut. Jika ingin melepas pijatan, kurangi tekanannya sedikit demi sedikit. Pengurangan tekanan secara bertahap dipercaya memampukan jaringan tubuh menyembuhkan dirinya sendiri, karena jaringan tersebut mendapat waktu merespons terhadap pengurangan tekanan.

Akupresur harus dilakukan saat rileks, terutama di tempat yang personal, dilakukan dengan duduk atau berbaring, tidak boleh melakukan akupresur tepat sebelum makan atau dalam keadaan kenyang ataupun ada keadaan sangat lapar(Wikihow, 2019). Saputri (2019) menyatakan bahwa pijat akupresur lebih efektifdibandingkan dengan aromaterapi lavender pada penurunan dismenore primer, sehingga pijat akupresur dapat dijadikan terapi alternatif yang digunakan wanita pada saat mengalami nyeri haid.

\section{Titik-titik untuk relaksasi tubuh}

Relaksasi tubuh dapat dilakukan dengan melakukan penekanan dengan kekuatan sedang pada titik stimulasi ini dengan ibu jari atau jari telunjuk dan jari tengah dan tahan selama 3 menit kemudian urut ke dua arah. Titik-titik tersebut antara lain :

1. Di bagian bawah tengkuk, dengan area jangkauan seluas satu jari ke arah sisi tulang belakang. 
2. Bagian di antara ibu jari dan jari telunjuk.

3. Di bagian telapak kaki, sekitar satu pertiga dari jempol kaki.

4. Di bagian kepala

5. Dibagian luar lutut, sekitar 3 inci ke bawah dari belakang lutut (Wisnuwardani, 2015).

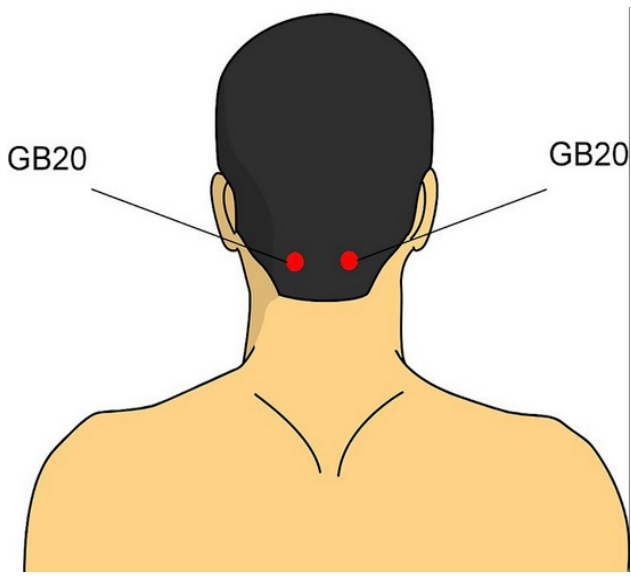

Gambar 7. Titik GB20

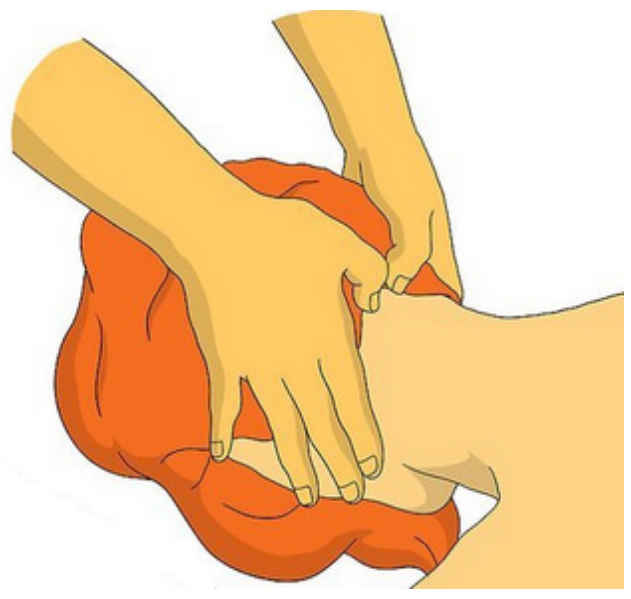

Gambar 8.

Cara melakukan penekanan pada titik GB20

- Gallbladder 20 (GB20) adalah titik yang disarankan untuk mengatasi sakit kepala, migrain, rabun mata atau kelelahan, kurang energi, serta gejala flu.

- GB20 terletak di leher.

- Untuk menemukan titiknya, gunakan jempol untuk menemukan cekungan di bagian dasar tengkorak. Titik ini berada sekitar $5 \mathrm{~cm}$ dari bagian tengah leher, yaitu di bawah tengkorak dan di samping otot-otot leher.

- Tekankan jempol ke dalam dan sedikit ke atas, mengarah ke mata.

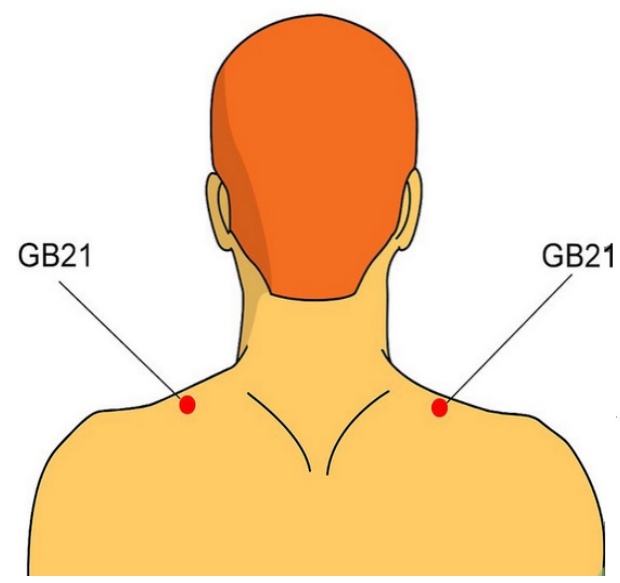

Gambar 9. Titik GB21

- Gallbladder 21(GB21), sering digunakan untuk mengatasi rasa sakit, kekakuan leher, bahu yang tegang, serta sakit kepala.

- GB21 terletak di bahu.

- Gunakan jari untuk menekan ke bawah secara stabil pada titik ini, bisa menekan 
titik di antara jari telunjuk dan jempol dengan tangan yang berlawanan. Lalu, pijat titik tersebut dalam gerakan mengarah ke bawah selama 4-5 detik, sembari pelan-pelan meredakan tegangannya.

- Berhati-hatilah saat menekan titik ini pada wanita hamil. Titik ini bisa mempercepat kelahiran.

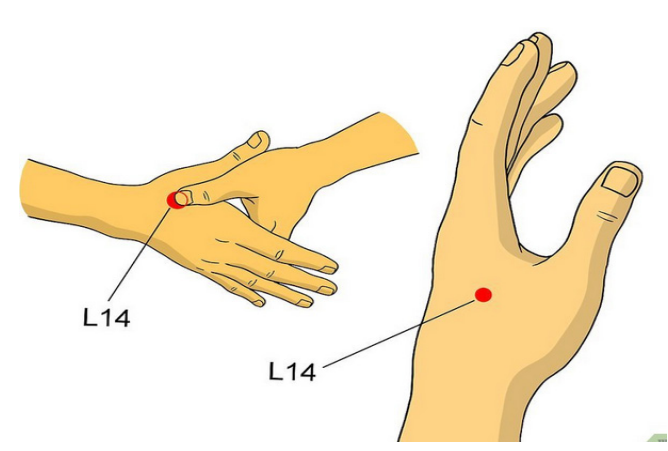

Gambar 10. Titik LI 4

- Large Intestine 4 (LI4), biasa digunakan untuk meredakan stres, sakit di area wajah, sakit kepala, sakit gigi, serta sakit kepala.

- LI4 bisa ditemukan di tangan, di antara jempol dan jari telunjuk.

- Untuk stimulasi pada area ini, tekan area di antara jari telunjuk dan jempol.

Tekanlah dengan kuat dan stabil sembari mencubitnya.

- Titik tekan ini juga dianggap bisa mempercepat kelahiran.
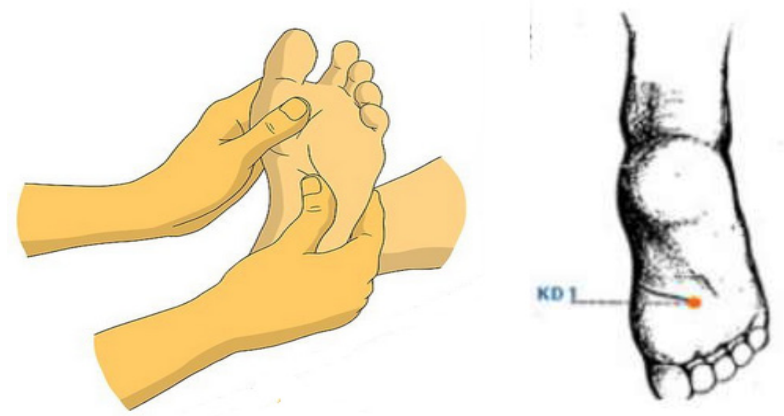

Gambar 11. Titik KD1

- Kidney 1 (KD1), sering digunakan untuk mengatasi rasa panik, ketegangan pikiran, mempunyai efek relaksasi.

- $\quad$ KD1 terletak pada $1 / 3$ bagian atas telapak kaki.

- Lakukan penekanan yang kuat ke dalam dan ke depan ke arah jempol kaki.

- Berhati-hatilah saat menekan titik ini pada wanita hamil. Titik ini bisa mempercepat kelahiran.

\section{Titik-titik untuk dismenorea}

Dismenorea adalah rasa tidak nyaman atau nyeri pada perut bagian bawah, yang terjadi pada masa awal menstruasi. Dismenorea merupakan menstruasi disertai rasa sakit yang hebat dan kram. Dismenorea berarti menstruasi yang sakit. Dismenorea bisa tersendiri atau merupakan bagian dari sindrom premenstrual. Istilah dismenorea primer dipakai untuk menstruasi yang sakit tanpa ada kaitannya dengan penyebab 


\section{GEMASSIKA: Jurnal Pengabdian Kepada Masyarakat}

Vol. 4 No. 1 Mei 2020

fisik. Sedangkan dismenorea sekunder ada kaitannya dengan penyebab fisik.

Dismenorea umumnya menyerang wanita yang sedang mengalami datang bulan. Semakin dewasa wanita, semakin berkurang rasa sakit yang dirasakan. Kondisi ini dapat hilang begitu wanita memiliki bayi. Nyeri haid dapat ditangani dengan mengurangi faktor-faktor risiko. Diskusikan dengan dokter untuk informasi lebih lanjut.

Gejala-gejala umum dari dismenore adalah nyeri pada perut bawah, kadang terasa intens, terasa tekanan pada perut, nyeri pada pinggang, punggung bawah, atau bagian dalam paha, mual dan muntah, feses yang cair, sakit kepala, serta pusing (Samiadi, 2016)

Dismenorea disebabkan oleh berkontraksinya otot rahim. Apabila otot berkontraksi terlalu kuat, nyeri muncul akibat putusnya pasokan oksigen pada jaringan otot di rahim. Berikut adalah kondisi yang dapat menyebabkan kram haid antara lain endometriosis: jaringan yang tersambung dengan rahim menjadi menempel dengan bagian luar rahim, biasanya pada tuba fallopi, indung telur atau pelvis, uterine fibroid, adenomyosis: jaringan terhubung dengan rahim bertumbuh hingga ke dinding rahim, menyebabkan rasa sakit, pelvic inflammation disease (PID): bakteri menular seksual dapat menyebabkan infeksi pada organ reproduksi wanita, cervical stenosis: jika bukaan cervix kecil yang mempengaruhi aliran menstruasi, menyebabkan rasa sakit dan meningkatkan tekanan pada rahim.

Ada banyak faktor risiko untuk dismenorea, yaitu usia di bawah 30 tahun, masa puber mulai sejak usia 11 atau ke bawah, mengalami perdarahan berat atau yang tidak normal selama menstruasi, belum pernah melahirkan, memiliki riwayat nyeri haid dalam keluarga, perokok.

Dismenorea adalah rasa sakit yang dirasakan oleh wanita saat menstruasi. Dismenorea biasannya disebabkan oleh pelepasan prostaglandin secara berlebihan, yaitu prostaglandin F2 alpha dari sel endometrium uterus. Banyak pengobatan dismenorea yang terlah berkembang di masyarakat baik terapi farmakologis maupun terapi non farmakologis. Terapi non farmakologis yang digunakan untuk mengurangi dismenorea salah satunya adalah akupresur (Efriyanthi, 2015; Laili, 2016).

Akupresur adalah penggunaan teknik sentuhan/kontak untuk menyeimbangkan saluran energy dalam tubuh atau Qi. Terapi akupresur dengan pemijatan atau penekanan 
pada titik LI 4 (Hegu) dan ST 36 (Zusanli) akan meningkatkan kadar endorphin sehingga lebih cepat menurunkan rasa nyeri (Setyowati, 2018; Efriyanthi, 2015). Tiga titik yang bisa dipijat untuk mengurangi dismenorea adalah atas mata kaki (LV 3), antara jempol dan telunjuk (LI 4), dan bawah tempurung lutut (ST 36) (Desideria, 2019). Titik akupresur LI 4 terbukti dapat menurunkan dismenorea. Hasil penelitian yang dilakukan Hasanah (2014) menunjukkan bahwa responden yang diberikan intervensi berupa akupresur pada titik LI 4 mengalami penurunan intensitas nyeri sebanyak 0,615 poin dan penurunan kualitas nyeri sebanyak 0,577 poin. Hasil penelitian tersebut menunjukkan ada penurunan yang signifikan setelah dilakukan akupresur terhadap dismenorea.

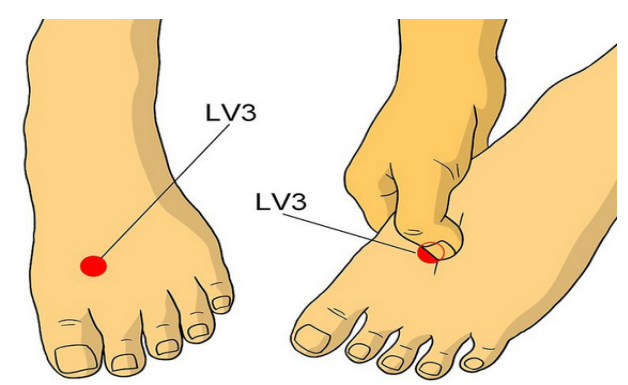

Gambar 12. Titik LV3

- Liver3(LV3), disarankan untuk mengatasi stres, sakit punggung bagian bawah, tekanan darah tinggi, kram menstruasi, sakit di tangan/kaki, insomnia, dan kecemasan.
- Titik ini terletak di antara jari kaki jempol dan telunjuknya.

- Cari lokasi titik dengan mengukur sepanjang dua jari di atas kulit yang menyatukan jari kaki pertama dan kedua. Tekan dengan kuat menggunakan benda tumpul.

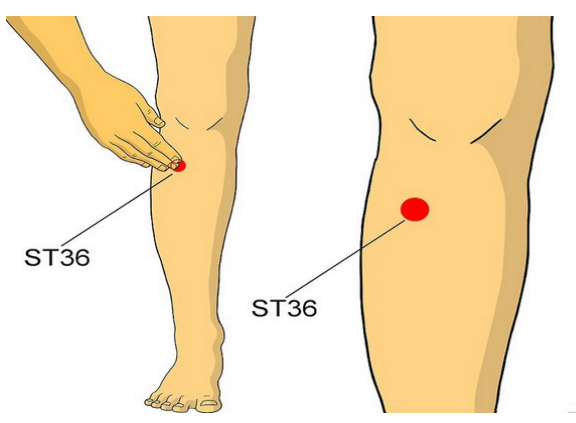

\section{Gambar 13. Titik ST 36}

- Stomach 36 (ST36), sering digunakan untuk masalah gastroinsetinal, rasa mual, mengatasi keinginan muntah, stres, meningkatkan imunitas tubuh, serta meredakan kelelahan.

- Titik ini bisa ditemukan di bawah tempurung lutut.

- Letakkan empat jari di bawah tempurung lutut di bagian depan betis, ada cekungan di antara tulang kering dan otot kaki di bawah jari-jari. Titik ini berada di bagian luar tulang.

- Tekan titik ini menggunakan kuku jari atau jempol. 
GEMASSIKA: Jurnal Pengabdian Kepada Masyarakat

Vol. 4 No. 1 Mei 2020

\section{KESIMPULAN DAN SARAN}

Kesimpulan dalam kegiatan pengabdian kepada masyarakat ini adalah bahwa kegiatan tersebut dapat meningkatkan pengetahuan dan keterampilan peserta tentang akupresur untuk relaksasi tubuh dan mengatasi dismenorea.
Rekomendasi untuk kegiatan pengabdian kepada masyarakat selanjutnya adalah penerapan metode thibbun nabawi untuk mengatasi masalah yang ada di masyarakat khususnya yang berhubungan dengan kesehatan reproduksi wanita dan kebidanan.

\section{DAFTAR PUSTAKA}

Desideria, B. 2019. Memijat 3 Titik Tubuh ini Ampuh Mengurangi Nyeri Hadi. Diakses tanggal 20 Mei 2019. https://www.liputan6.com/health/read/3957433/memijat-3-titik-tubuh-iniampuh-mengurangi-nyeri-haid?related=dable\&utm_expid=.9Z4i5ypGQeGiS7w9arwTv Q.1\&utm_referrer=https $\% 3 \mathrm{~A} \% 2 \mathrm{~F} \% 2 \mathrm{Fwww}$.google.com $\% 2 \mathrm{~F} \#$.

Efriyanthi, S. 2015. Pengaruh Terapi akupresur sanyinjiao point terhadap intensitas nyeri dismenore primer pada mahasiswi semester VIII Program Studi Ilmu Keperawatan. Coping: Community of Publishing in Nursing. Vol. 3 No. 2. http://www.ojs.unud.ac.id/ index.php/coping/article/view/15681.

Hasanah, O. 2014. Efektivitas akupresur terhadap dismenorea pada remaja putri. Jurnal online Mahasiswa Program Studi Ilmu Keperawatan Universitas Riau. https://www.neliti.com/ publications/188169/efektifitas-akupresur-terhadap-dismenore-pada-remaja-putri.

Julianti, dkk. 2014. Efektivitas akupresur terhadap dismenore pada remaja putri. Jurnal Online Mahasiswa (JOM) PSIK UNRI. https://www.neliti.com/publications/188169/efektifitasakupresur-terhadap-dismenore-pada-remaja-putri.

Laili, F. 2016. Pengaruh terapi akupresur Nie Guan terhadap intensitas nyeri dismenore pada mahasiswi program studi bidan pendidik (DIV) Minat Klinik Fakultas Ilmu Kesehatan Universitas Kadiri tahun 2016. Diakses tanggal 2 Mei 2020. http://jhj.fik-unik.ac.id/ index.php/JHJ/article/view/105.

Majid, Y.A dan Rini, P.S. 2016. Terapi Akupresur memberikan rasa tenang dan Nyaman serta mampu menurunkan tekanan Darah Lansia. Jurnal Aisyiyah: Jurnal Ilmu Kesehatan. https://aisyah.journalpress.id/index.php/jika/article/viewFile/11/10

74 Pelatihan Akupresur untuk Relaksasi Tubuh... 
Meita, A, dkk. 2018. Perbedaan intensitas nyeri dismenore sebelum dan sesudah diberikan terapi nonfarmakologi (akupresur) pada mahasiswi Fakultas Ilmu Kesehatan Universitas Tribhuwana Tunggadewi Malang angkatan 2009 dan 2010. Nursing News: Jurnal Ilmiah Keperawatan. https://publikasi.unitri.ac.id/index.php/fikes/article/view/1108.

Olivia, F. 2013. Awet Muda ala Korea.Jakarta: PT Elex Media Komputindo.

Ridwan, M dan Herlina. 2015. Metode Akupresur untuk meredakan nyeri haid. Jurnal Kesehatan Metro Sai Wawai, Volume VIII, No. 1 Edisi Juni 2015, ISSN: 19779-469X. http://www. ejurnal.poltekkes-tjk.ac.id/index.php/JKM/article/view/170.

Samiadi, L.A. 2016. Apa Itu Dismenorea?. Direview tanggal: Desember 14, 2016. Terakhir Diedit: Desember 14, 2016. Diakses tanggal 11 Februari 2019. https://hellosehat.com/ penyakit/dismenore/

Saputri, A. 2019. Perbedaan efektivitas aromaterapi lavender dan pijat akupresur terhadap penurunan dimenore primer pada siswi madrasah aliyah di Pondok Pesantren Darul A'Mal Metro Tahun 2019. Repositori Poltekkes Tanjungkarang. http://repository. poltekkes-tjk.ac.id/407/.

Setyowati, H. 2018. Akupressur untuk Kesehatan Wanita Berbasis Hasil Penelitian. Magelang : UNIMMA PRESS.

Wikihow. 2019. Cara Melakukan Akupresur. Diakses tanggal 20 Mei 2019. https://id.wikihow. com/Melakukan-Akupresur.

Wisnuwardani, D.P. 2015. Pijat 5 titik ini agar Tubuh Lebih Bersinergi. Diakses tanggal : 20 Mei 2019. https://www.liputan6.com/health/read/2317465/pijat-5-titik-ini-agar-tubuhlebih-berenergi.

Yati, S. 2019. Pengaruh Tehnik Akupresur terhadap penurunan tingkat nyeri pada siswi kelas $X$ yang mengalami dismenore primer di SMA Negeri 2 Kota Sungai Penuh tahun 2015. Jurnal Penelitian dan Kajian Menara Ilmu Universitas Muhammadiyah Sumatera Barat. Diakses tanggal 2 Mei 2020. https://jurnal.umsb.ac.id/index.php/menarailmu/article/ view/1362/1196. 